\title{
A new sauropod dinosaur from the Lower Cretaceous Cedar Mountain Formation, Utah, USA
}

Michael P. Taylor, Mathew J. Wedel, and Richard L. Cifelli

Acta Palaeontologica Polonica 56 (1), 2011: 75-98 doi: http://dx.doi.org/10.4202/app.2010.0073

Brontomerus mcintoshi is a new genus and species of sauropod dinosaur from the Hotel Mesa Quarry in Grand County, Utah, USA, in the upper part of the Ruby Ranch Member (Aptian-Albian) of the Lower Cretaceous Cedar Mountain Formation. It is known from at least two fragmentary specimens of different sizes. The type specimen is OMNH 66430, the left ilium of a juvenile individual; tentatively referred specimens include a crushed presacral centrum, a complete and well-preserved mid-to-posterior caudal vertebra, the partial centrum of a distal caudal vertebra, a complete pneumatic anterior dorsal rib from the right side, the nearly complete left scapula of a much larger, presumably adult, individual, and two partial sternal plates. Brontomerus is diagnosed by five autapomorphies of the type specimen: preacetabular lobe $55 \%$ of total ilium length, longer than in any other sauropod; preacetabular lobe directed anterolaterally at $30^{\circ}$ to the sagittal, but straight in dorsal view and vertically oriented; postacetabular lobe reduced to near absence; ischiadic peduncle reduced to very low bulge; ilium proportionally taller than in any other sauropod, 52\% as high as long. In a phylogenetic analysis, Brontomerus was recovered as a camarasauromorph in all most parsimonious trees, but with uncertain position within that clade. The large preacetabular lobe of the ilium anchored powerful protractor and abductor muscles, but precise interpretation is impossible without functionally related elements such as femora and proximal caudal vertebrae. Brontomerus is the eighth sauropod genus named from the Early Cretaceous of North America, and more remain to be described: North American sauropod diversity did not decline catastrophically at the end of the Jurassic as often assumed. The most striking differences between Late Jurassic and Early Cretaceous sauropod faunas in North America is that the former are abundant and dominated by diplodocids, whereas the latter are comparatively scarce—though still diverse-and dominated by macronarians.

Key words: Dinosauria, Sauropoda, Camarasauromorpha, Brontomerus, Brontomerus mcintoshi, diversity, Early Cretaceous, North America.

Michael P. Taylor [dino@miketaylor.org.uk], Department of Earth Sciences, University College London, Gower Street, London WC1E 6BT, United Kingdom; Mathew J. Wedel [mathew.wedel@gmail.com], College of Osteopathic Medicine of the Pacific and College of Podiatric Medicine, Western University of Health Sciences, 309 E. Second Street, Pomona, California 91766-1854, USA; Richard L. Cifelli, [rlc@ ou.edu], Sam 
Noble Oklahoma Museum of Natural History, 2401 Chautauqua, Norman, Oklahoma 73072, USA.

This is an open-access article distributed under the terms of the Creative Commons Attribution License (for details please see creativecommons.org), which permits unrestricted use, distribution, and reproduction in any medium, provided the original author and source are credited.

Forif Full text $(1,081.8 \mathrm{kB})$ 